\title{
ASO Visual Abstract: Influence of Damaged Stomach on Anastomotic Leakage After Cervical Esophagogastrostomy for Patients with Esophageal Cancer
}

Suguru Maruyama, MD, PhD, Akihiko Okamura, MD, PhD, Yasukazu Kanie, MD, Kei Sakamoto, MD, Daisuke Fujiwara, MD, PhD, Jun Kanamori, MD, PhD, Yu Imamura, MD, PhD, FACS, and Masayuki Watanabe, MD, PhD, FACS

Department of Gastroenterological Surgery, Cancer Institute Hospital of Japanese Foundation for Cancer Research, Tokyo, Japan

This study (https://doi.org/10.1245/s10434-021-10145-4) investigated the association between damaged stomach and the incidence of anastomotic leakage in patients who underwent gastric tube reconstruction after esophagectomy. The damaged stomach was an independent risk factor for the occurrence of anastomotic leakage.

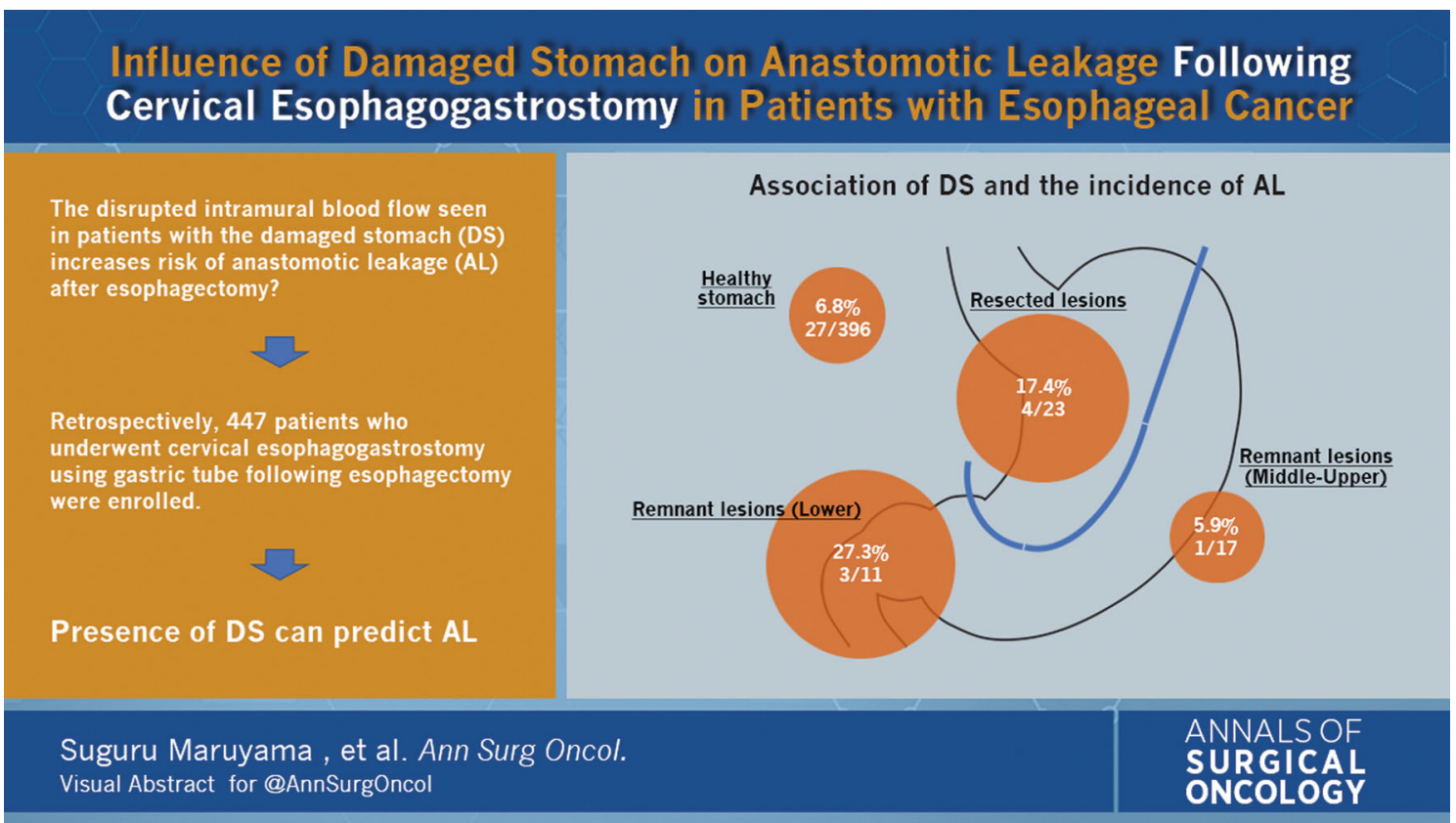

(C) Society of Surgical Oncology 2021

Published Online: 31 May 2021

A. Okamura, MD, PhD

e-mail: akihiko.okamura@jfcr.or.jp

DISCLOSURES There are no conflicts of interest.

Publisher's Note Springer Nature remains neutral with regard to jurisdictional claims in published maps and institutional affiliations. 